\title{
Indústria mineral
}

\author{
IRAN F. MACHADO
}

$\mathrm{N}$

OS ÚlTiMOS DEZ ANOS houve uma sucessão de eventos nas esferas política, econômica, social e institucional, acarretando mudanças profundas nas relações internacionais entre os principais agentes que atuam no mercado de bens minerais. Em primeiro lugar, o fim do mundo bipolar, que exercia enorme influência nas disponibilidade e estocagem de minerais metálicos, de importância estratégica para a indústria bélica. Conseqüentemente, as preocupações no campo da geopolítica migram substancialmente para o campo da geoeconomia, em que tratados e acordos bilaterais ou multilaterais perdem o significado tradicional e podem ser substituídos por contratos na área comercial. Em segundo lugar, o paradigma do desenvolvimento econômico, calcado na industrialização, cede lugar ao paradigma da informação; em outras palavras, a siderurgia torna-se o símbolo de uma era passada, enquanto a indústria eletrônica, ou o chip, encontra terreno fértil para o seu crescimento vertiginoso.

$\mathrm{Na}$ esteira dessa mudança vem outra tendência, mais recente, com a seguinte mensagem: não transporte átomos, e sim elétrons. A telemática ganhou contornos inimagináveis 10 ou 15 anos atrás, em função da irrupção das redes de computadores em todo o mundo, alterando significativamente a transmissão de dados e imagens. Em terceiro lugar, o crescimento econômico passou a ocorrer a taxas mais moderadas a partir de 1973 - primeiro choque do petróleo -, o que impôs um nível de competição maior entre as empresas, inclusive as transnacionais, ávidas por conquistar novos mercados ou ampliar a sua fatia de um mercado já existente; a partir daí, a globalização passou a constar da agenda dessas empresas como sinônimo de manutenção do status quo ou da própria sobrevivência. Em quarto lugar, após mais de 200 anos do início da Revolução Industrial, a natureza mostra sinais de fadiga exigindo maior consciência da sociedade e medidas eficazes para a preservação do meio ambiente fragilizado. Nasce finalmente o conceito de desenvolvimento sustentável, balizado pela preocupação com o bem-estar das gerações futuras. Em quinto lugar, os organismos internacionais percebem com clareza que o crescimento econômico não consegue por si só amenizar os problemas da pobreza, da miséria e da fome que assolam uma parcela imensa da população mundial, principalmente fora dos países desenvolvidos. Em sexto lugar, o fantasma do desemprego aparece na década de 90 como o denominador comum das falhas inquietantes das políticas públicas, quer em países ricos, quer em países pobres. Enquanto as políticas macroeconômicas buscam desesperadamente gerar empregos, o universo microeconômico substitui vorazmente o homem pela máquina, ao perseguir a maximização do lucro para satisfazer o desejo insaciável de acionistas anônimos, os novos donos do mundo. A crise das bolsas asiáticas no último trimestre de 1997 é um indicativo da complexidade do mundo financeiro nos dias atuais. Trata-se de uma equação peri- 
gosa, quando confrontada com o relógio da população mundial, que vem crescendo à razão de 1 bilhão de pessoas a cada 11 anos, segundo dados da ONU.

Os principais corolários das mudanças já esboçadas, impactando o setor mineral, seriam:

- menor taxa de crescimento no consumo de bens minerais, em particular do segmento dos metálicos: as guerras sempre constituíram eventos especialmente promotores do crescimento rápido do consumo de metais ferrosos e não-ferrosos, além de outros materiais;

- preço declinante das commodities não-energéticas ao longo da segunda metade do século atual, com flutuações individualizadas e também cíclicas, em função da economia internacional (figura 1);

- preços de algumas commodities administrados por grandes consumidores (exemplo típico, o minério de ferro produzido pelo Brasil e pela Austrália, em que a rentabilidade da CVRD e da BHP no segmento de minério de ferro é ditada pelos cálculos econométricos das grandes siderúrgicas japonesas e alemãs); o preço do produtor, que outrora existiu para alguns metais como cobre, alumínio e níquel controlados por oligopólios, tornou-se algo superado devido ao fortalecimento do poder de barganha do consumidor nos mercados dos países desenvolvidos; hoje, o preço desses metais é cotado em bolsas de mercadorias no mundo inteiro;

- automação das operações de exploração, lavra e tratamento de minérios: menos empregos na indústria mineral e maiores exigências na contratação de mão-de-obra em todos os níveis;

- maior racionalização no uso de materiais: o uso crescente da informática permite que se reduza o desperdício no consumo de materiais, de origem mineral ou de qualquer outra origem;

- aparecimento, a partir da década de 70, de legislação ambiental crescentemente restritiva, criando obrigações ou adaptações na cadeia produtiva e custos econômico-financeiros às vezes insuportáveis para algumas empresas de mineração;

- mudanças geográficas de operações mineiras para países do Terceiro Mundo, em busca de uma legislação mais branda e de menor impacto sobre a rentabilidade dessas operações;

- a crise econômica que se abateu sobre um número expressivo de países em desenvolvimento teve como conseqüência o desenho de uma nova legislação - mineral e fiscal - mais atrativa para os investimentos estrangeiros, avidamente disputados por aqueles países.

Como reagir às ações simultâneas de todos esses fatores intervindo no dia a dia da indústria mineral? Os itens seguintes procuram realçar os principais tópicos que posicionam a indústria face à globalização. $\mathrm{O}$ principal foco neste artigo é o 
setor de bens minerais metálicos da indústria mineral organizada, não sendo contemplados itens como mineração em áreas urbanas, mineração em terras indígenas e atividade garimpeira.

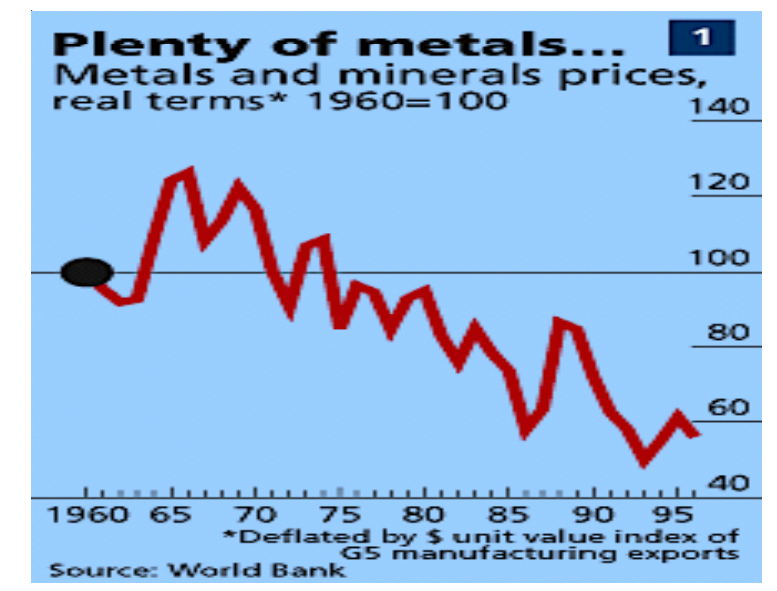

Figura 1: Preços declinantes de metais e minerais (1960-96) Fonte: The Economist, $20 \mathrm{dez} .97$

\section{A competição na arena internacional}

Ocupando o $5^{\circ}$ lugar no mundo em extensão territorial, o Brasil apresenta-se como o maior produtor de nióbio do mundo, o $2^{\circ}$ em produção de minério de ferro, o $4^{\circ}$ para magnesita, estanho, bauxita e caulim, o $5^{\circ}$ para manganês, amianto, lítio e grafita, o $6^{\circ}$ para talco e fluorita, e o $7^{\circ}$ para rochas ornamentais, cromo e diamante (DNPM, 1996). O valor total da produção mineral atingiu em 1996 a cifra de US\$ 15 bilhões, o que corresponde a cerca de $2 \%$ do PIB (US\$ 751,1 bilhões). Desse valor, a produção de petróleo e gás natural se aproxima de US\$ 6 bilhões (Gurmendi, 1996). Dentro do Mercosul, o Brasil é líder na produção de alumínio, cimento, ferroligas, ouro, minério de ferro, manganês, aço e estanho. Dispondo tanto de recursos identificados quanto de não-descobertos, o país é um dos mercados emergentes mais importantes do mundo, correspondendo a um terço da economia da América Latina e à nona do mundo. Apesar disso, em função das limitações de suas características geológicas e metalogenéticas, o Brasil é grande importador de molibdênio, vanádio, platina, potássio, carvão metalúrgico, concentrados de chumbo e cobre, e ainda de enxofre, todos com dependência superior a $50 \%$ do consumo (Barboza, 1995). Em 1995, as importações de produtos de origem mineral alcançaram o valor de US\$ 9,3 bilhões, aí incluída a conta-petróleo.

Ao compararmos o seu privilegiado patrimônio mineral com outros países de grande extensão territorial, constata-se que os seus grandes concorrentes são a 
Comunidade de Estados Independentes (CEI), a China, a Austrália e a Índia. Segue-se um quadro comparativo entre a indústria mineral brasileira e a dos seus concorrentes (Hargreaves et al., 1994).

Quadro 1

Comparação entre a indústria mineral do Brasil e a de países concorrentes

\begin{tabular}{|c|c|c|}
\hline País & $\%$ do PIB & Principais minerais produzidos \\
\hline Austrália & 8 & $\begin{array}{l}\text { Bauxita, carvão, chumbo, cobre, diamante, } \\
\text { manganês, minerais de ferro, níquel, ouro, } \\
\text { prata, tântalo, urânio e zirconita }\end{array}$ \\
\hline Brasil & 2,7 & $\begin{array}{l}\text { Amianto, bauxita, caulim, diamante, estanho, } \\
\text { grafita, lítio, magnesita, manganês, minério } \\
\text { de ferro, nióbio, ouro e petróleo }\end{array}$ \\
\hline CEI & 18 & $\begin{array}{l}\text { Carvão, chumbo, cobalto, cobre, cromita, } \\
\text { diamante, magnésio, manganês, MGP, } \\
\text { minério de ferro, níquel, petróleo e tungstênio }\end{array}$ \\
\hline China & 13,5 & $\begin{array}{l}\text { Antimônio, bauxita, bismuto, carvão, } \\
\text { estanho, minério de ferro, petróleo e zinco }\end{array}$ \\
\hline Índia & 6 & $\begin{array}{l}\text { Bauxita, carvão, cromita, manganês, } \\
\text { minério de ferro, petróleo, terras-raras, } \\
\text { titânio, zinco e zirconita }\end{array}$ \\
\hline
\end{tabular}

Ao disputar os investimentos estrangeiros, surgem vantagens e desvantagens para cada um dos países concorrentes. Com os desdobramentos da perestroika, a Rússia parecia o país ideal para captar investimentos externos: patrimônio mineral invejável, alta disponibilidade de engenheiros e cientistas, mão-de-obra especializada, infra-estrutura já implantada (inclusive na Sibéria) etc. Todavia, ficou patente que algumas dificuldades estão ali presentes, conforme a experiência de algumas empresas ocidentais (Dorian \& Kort, 1996). Segue uma lista desses problemas:

- direitos minerários mal definidos;

- sistemas bancários e mercados financeiros pouco desenvolvidos, instáveis e pouco regulados;

- burocracia excessiva;

- infra-estrutura inadequada, notadamente em transporte, comunicações e energia;

- incerteza quanto à coerência de políticas e regulamentos do governo;

- inquietação social em potencial; 
• inflação alta e volátil;

- moeda instável e não-conversível;

- metodologias contábeis muito variadas;

- negociadores habilidosos e intransigentes;

- desconfiança generalizada com cidadãos estrangeiros;

- resistência à supervisão gerencial por terceiros.

Outra constatação refere-se a que a maioria das antigas repúblicas soviéticas padece de problemas mais gerais: recessão econômica, corrupção, tensões étnicas e nacionalismo (às vezes acompanhado de fervor religioso).

De modo geral, os outros países latino-americanos e o Canadá não são concorrentes importantes do Brasil no comércio internacional, visto serem grandes exportadores de minerais não-abundantes em nosso subsolo: cobre, chumbo, zinco, níquel, prata, carvão metalúrgico, sais de potássio entre outros bens minerais importados via de regra pelo Brasil.

Alguns autores estrangeiros têm a percepção de que a liberalização das oportunidades minerais nos países em desenvolvimento e nos países ex-socialistas, significará um ganho no que concerne ao desempenho da indústria mineral (Warhurst \& Bridge, 1997). Uma das principais alegações diz respeito a que as empresas estrangeiras aplicarão tecnologias limpas, idênticas àquelas utilizadas nos países de origem. A experiência brasileira demonstra que isto pode ou não acontecer no dia a dia da mineração. Segundo consta, existem algumas medidas tímidas em poucos estados, onde uma caução vem sendo exigida para a futura recuperação das áreas degradadas. Todavia, esta exigência tem ocorrido da parte do Ministério Público, e não dos órgãos ambientais (1). Por outro lado, há uma longa lista de empreendimentos que ignoraram as boas normas de preservação ambiental, inclusive na Amazônia. Uma das exceções foi o fechamento da mina de cobre e ouro Cabaçal (RTZ, 1994), no estado de Mato Grosso, operada pela Rio Tinto, sediada em Londres. A mina, localizada no município de Rio Branco, esteve em atividade durante cinco anos, produzindo $300 \mathrm{mil} \mathrm{t} / \mathrm{a}$ de minério por meio de lavra subterrânea. Sua produção acumulada atingiu $4.700 \mathrm{~kg}$ de ouro, $2.700 \mathrm{~kg}$ de prata e $7.800 \mathrm{t}$ de cobre, por extração de um milhão de toneladas de minério, daí resultando 100 mil t de estéril. Em 1990 foi aprovado pelo órgão ambiental do estado o Plano de Recuperação de Áreas Degradadas (PRAD) submetido pela empresa. O plano estabelecia as ações de reabilitação das áreas degradadas pela atividade minerária, tanto durante a fase de operação da mina quanto após o encerramento das fases produtivas. Depois de ser analisado o plano de recuperação, a Rio Tinto recebeu o Certificado de Descomissionamento, outorgado pela Secretaria Especial do Meio Ambiente daquele estado. Embora se trate de uma mina de pequenas dimensões, é gratificante observar que a iniciativa privada vem demonstrar a sua responsabilidade com relação à preservação do meio ambiente. 
Do ponto-de-vista dos investimentos realizados após a liberalização, os números impressionam: entre 1990 e 1995, os investimentos novos na América Latina totalizaram US\$ 238 bilhões, enquanto as despesas com pesquisa mineral cresceram cinco vezes, atingindo US\$ 500 milhões por ano. No momento, é difícil prever qual será o passivo ambiental resultante desses investimentos à luz da legislação ambiental tolerante em vigor em toda a América Latina. Este tópico será retomado mais adiante, ao longo deste artigo.

Poucos estudos têm sido realizados no Brasil sobre a competitividade internacional da indústria mineral. A flexibilização das regras do jogo tende a seguir padrões estabelecidos para outros países da região, notadamente Chile e México. Não obstante os atrativos que possam ser criados, não existe artifício que substitua uma jazida de classe internacional, conforme será discutido a seguir.

\section{A ineficácia do modelo baseado em reservas de baixos teores e avanços tecnológicos}

Quando, nas décadas de 50 e 60, o movimento nacionalista varreu um grande número de países em desenvolvimento dotados de patrimônio mineral expressivo, uma das saídas para as empresas transnacionais foi a tentativa de trabalhar minérios mais pobres, ou jazidas mais profundas encontrados em seu território ou no de países alinhados. Politicamente elas estariam mais seguras, poucos seriam os problemas ligados à infra-estrutura, a mão-de-obra tinha nível profissional adequado, de modo que a questão crítica e não-resolvida seria a tecnologia necessária para competir em posição vantajosa com aqueles países politicamente instáveis, porém detentores de melhores reservas. Em seguida ao primeiro choque do petróleo ocorrido em 1973, quando havia o receio da formação de cartéis minerais inspirados no modelo da OPEP, os países industrializados investiram pesadamente em P\&D de modo a contrabalançar as vantagens dos concorrentes menos desenvolvidos. A partir dessa época surgiram a lixiviação em pilha para extração de ouro, os avanços da hidrometalurgia, a extração de cobre via SX-EW, o uso de caminhões fora-de-estrada de mais de 200 t de capacidade, de equipamentos gigantescos de lavra convencional ou contínua (walking draglines, stacker-reclaimers etc.), de explosivos mais seguros, do tipo ANFO, o uso intensivo de equipamentos e processos computadorizados com controle remoto, dentre outros.

Mesmo assim, todo esse arsenal não criou um diferencial imbatível para as minas dos países desenvolvidos. Além disso, quando algumas dessas tecnologias são aplicadas a jazidas ricas do Terceiro Mundo, o resultado econômico-financeiro na bottom line é duplamente vitorioso. Talvez o exemplo mais gritante do esforço empreendido pelos países industrializados ao tentar minimizar a dependência do subsolo do Terceiro Mundo seja o programa de recuperação de nódulos submarinos, ricos em manganês, cobre, níquel, cobalto e outros metais. Este programa, subvencionado por grandes empresas norte-americanas, canadenses, alemãs e japonesas, levou à construção de protótipos de navios especializados na extração desses nódulos a 
profundidades maiores que 200 metros. O programa arrefeceu quando começaram a surgir problemas legais, dentre eles a declaração pela Assembléia Geral da ONU de que tais recursos naturais constituiriam parte do patrimônio comum da humanidade, e não das empresas ou países diretamente interessados.

Ainda no ano de 1990 uma comissão de peritos norte-americanos julgava que o governo deveria se empenhar no desenvolvimento de novos processos tecnológicos que permitissem o aproveitamento de minérios mais pobres existentes nos EUA, Canadá e em outros países politicamente estáveis (National Research Council, 1990). Todavia, naquela época alguns países em desenvolvimento, como o Chile, já ensaiavam os primeiros passos no sentido de flexibilizar a sua legislação mineral com vistas a atrair o capital estrangeiro. Desde então, uma longa lista de países - mais de 70 - aderiu a esta tendência, buscando disputar os investimentos externos disponíveis para projetos de mineração. À medida que um número crescente de países, inclusive do Primeiro Mundo, viam crescer o seu déficit público, houve uma reestruturação de seus programas de investimento, no sentido de redesenhar o papel do Estado, reduzindo ou eliminando a sua função empresarial. Em conseqüência dessas políticas, até países como Suécia e Finlândia passaram a desenvolver programas agressivos de privatização, embora o número mais expressivo refira-se aos países membros da extinta URSS e a seus aliados da Europa Oriental, além dos países em desenvolvimento.

Dentro deste novo quadro, as transnacionais de mineração enfrentam hoje a situação mais favorável a elas de toda a história, quando países dos três blocos debatem-se em acirrada disputa para atração do investimento estrangeiro. Considerando todos os fatores já mencionados envolvidos nessa equação, as transnacionais encontram opções crescentemente vantajosas para abrir novas minas fora do território de sua matriz. Tal fato significa, em termos práticos, que o modelo baseado na busca de jazidas de teores mais baixos, conjugado com maior capacitação tecnológica, tornou-se pouco competitivo ou de menor prioridade face à superoferta de oportunidades em países que necessitam continuar o aproveitamento dos seus recursos minerais para promover o seu desenvolvimento econômico. A própria extinção em 1995 do Bureau of Mines dos EUA obedece a esta lógica (Machado, 1997a). Tal situação seria completamente diferente caso a Guerra Fria, baseada num mundo bipolar, tivesse se prolongado até os dias atuais ou, então, se a maioria das nações dependentes da mineração conseguisse manter o equilíbrio de suas contas nacionais.

\section{A nova busca do Eldorado}

Assumindo um comportamento extremamente pragmático as transnacionais, a partir da segunda metade da década de 80 , vem investindo crescentemente em países menos desenvolvidos, onde a vantagem competitiva básica é a presença de jazidas de classe internacional. Por que seria este fator a chave do sucesso? Se tomarmos por comparação a indústria de transformação, a corrida pela excelência teve como paradigmas os conceitos de qualidade total, reengenharia, downsizing, justin-time etc., amplamente divulgados e discutidos em inúmeros simpósios, seminá- 
rios e outros eventos realizados no mundo inteiro. No mundo mineral, a corrida é diferente: onde estão as jazidas que asseguram uma posição imbatível? A situação é semelhante no mundo do petróleo: onde estão os campos gigantes ou aqueles de baixo custo de produção? Se este fundamento não fosse verdadeiro, as grandes transnacionais do cobre continuariam em intensa atividade nos estados de Utah, Montana e Arizona, refinando as suas técnicas de gestão e trabalhando em profundidades crescentes, mas com risco político igual a zero, dentro da alternância monótona entre os partidos Republicano e Democrata assumindo o poder ou a maioria no Congresso. Na área de petróleo e gás natural, as empresas continuariam indefinidamente perfurando os seus poços no Texas e em Oklahoma às custas de investimentos continuados em tecnologias mais sofisticadas.

Cabe esclarecer que a valorização intrínseca das jazidas ricas não é uma descoberta recente das transnacionais de mineração. Quando companhias inglesas chegaram ao Brasil em torno de 1824, elas já estavam conscientes de que as jazidas de ouro de Minas Gerais eram mais atrativas do que as seculares jazidas existentes na Europa ou no Oriente Médio. Ou seja, a globalização para a indústria do ouro teve início há mais de um século e meio para empresas estrangeiras organizadas, interessadas em nosso potencial. Indo mais longe, desde o tempo dos Bandeirantes, no período Colonial, o ouro do Brasil vinha sendo extraído pelos portugueses e comercializado com os ingleses pelo Tratado de Methuen. Preterir Brasil, Austrália ou África do Sul, em benefício de países europeus geograficamente mais próximos seria, na época, um ato de insanidade empresarial.

Nos dias atuais, a corrida do ouro no Brasil tem como principal destino a Amazônia, em virtude da existência de enorme potencial já comprovado pela atividade garimpeira na província do Tapajós, em Serra Pelada, no estado de Mato Grosso e em dezenas de outras áreas. Não são muitos os países que podem oferecer a oportunidade de produzir ouro a custos menores que US\$250 por onça troy. Esta expectativa explica o interesse na Amazônia demonstrado por empresas de grande porte e também por empresas juniors canadenses e norte-americanas. Em entrevista publicada na revista Brasil Mineral (Brito \& Alves, 1997), o engenheiro Miguel Navarrete, diretor-geral do Departamento Nacional da Produção Mineral, revelou que os investimentos em pesquisa mineral realizados no Brasil em 1996 atingiram US\$ 120 milhões, um crescimento de 80\% sobre o ano anterior. Para 1997 a previsão era de US\$ 180 milhões, algo conservadora, segundo o entrevistado.

Antes da década de 80 três fatores inibiram as maiores investidas do capital estrangeiro no subsolo alheio:

- o risco político dos países em desenvolvimento, caracterizados por regimes ditatoriais, revoluções, golpes de Estado etc., que ameaçava a continuidade das operações ou a repatriação dos investimentos a serem realizados;

- a falta de infra-estrutura desses países, considerando que as jazidas não costumam se localizar junto ao litoral, o que mudou ao longo do tempo, muito mais pelos avanços tecnológicos do que pela construção dessa infra- 
estrutura para atender a outros projetos;

- a restrição aos investimentos estrangeiros nos países socialistas, limitando o comércio internacional de matérias-primas minerais.

A evolução da mineração no contexto internacional, desde a década de 60 até a década atual, é mostrada de modo esquemático nas figuras 2,3 e 4 . Na figura 2 é representada, na verdade, a lógica que explica o deslocamento das transnacionais para o Terceiro Mundo em busca de jazidas mais ricas, inexistentes no Primeiro Mundo em decorrência de um longo processo de industrialização, ávido pelo consumo de matérias primas a curta distância no primeiro momento. Todavia, o fim do colonialismo na primeira metade do século atual levou ao surgimento de aspirações nos campos político e econômico no seio das novas nações que viriam a desaguar no movimento de nacionalização de empreendimentos mineiros na América Latina e na África. Na figura 3 é explicitada a crise resultante da ineficácia do modelo baseado em reservas de baixos teores e inovações tecnológicas, quando o meio ambiente dos países desenvolvidos acumulou um passivo ambiental que exigiu medidas radicais, conforme será discutido no item sobre a legislação ambiental. Finalmente, na figura 4 é visualizada a volta do equilíbrio ao suprimento de matérias-primas minerais para os países desenvolvidos. Premidos pela necessidade de retomar o desenvolvimento econômico, os países do Terceiro Mundo foram induzidos a promover mudanças em sua política e legislação mineral com o objetivo de atrair novamente o capital estrangeiro. Em paralelo, a sua legislação ambiental se implanta, mas de modo tolerante, procurando conciliar as aspirações das empresas de mineração, seja nacionais, seja estrangeiras. Da combinação de políticas públicas redesenhadas por inúmeros países resultam oportunidades de negócios consideradas inéditas na história da mineração para as transnacionais.

Deve-se reconhecer que no final da década de 80, continuando pelo início da atual, os contextos político, econômico e social mudaram radicalmente. Conforme explicitado de forma inequívoca no documento relativo ao Plano Estratégico do USGS 1996-2005, qualquer bem mineral necessário ao consumo da indústria norteamericana está hoje disponível em algum lugar do planeta; a sua aquisição depende meramente de uma operação comercial, ou seja, de um contrato de compra e venda. Esta segurança é tão consensual na formulação das políticas globais daquele país, que nos últimos três anos ocorreu a extinção do seu Bureau of Mines e quase teve a mesma sorte o Serviço Geológico. Tomada tal decisão, o governo norte-americano passou a adotar políticas de suprimento de bens minerais relativamente similares às da Alemanha e do Japão, potências econômicas desprovidas do excessivo zelo com a auto-suficiência desses bens.

Por outro lado, não se deve concluir precipitadamente que o bem mineral se transformou em algo extremamente banal, conforme anunciado pelo governo brasileiro durante a privatização da Companhia Vale do Rio Doce. Ocorre que, dentro da conjuntura atual do comércio internacional, fortemente controlado por organismos financeiros, pelo G-7 e pela OCDE, não há qualquer problema de escassez. 
Assim, alguns bens minerais tenderão a ser tratados, no futuro, mais como utility - semelhante a água, gás ou energia elétrica - do que como commodity, conforme está esquematizado na figura 5 (2). Mais do que em qualquer outro período da história, o poder de barganha está do lado do consumidor, e não do produtor de minerais ou metais. Num cenário de superoferta da maioria dos bens minerais, o seu preço relativo continua em queda gradual e, ao longo de toda a segunda metade deste século, de forma contínua. Somente o rápido aumento no consumo, ou a montagem de oligopólios ou cartéis para alguns desses bens minerais, poderia reverter este quadro. É sabido, porém, que esta última hipótese não teria qualquer sustentação nos dias atuais devido a inúmeras razões. Em conseqüência dessa administração de preços praticados em alguns setores da indústria mineral, da forte concorrência entre produtores situados em todas as latitudes, agravada pelos custos crescentes de controle ambiental, empresas norte-americanas tradicionais em mineração vêm sendo transferidas paulatinamente para capitais europeus, japoneses ou australianos, sinalizando que o investidor norte-americano hoje está menos interessado em mineração do que no passado. Deve-se recordar que nas décadas de 20 e 30 as ações das empresas de mineração eram notórias blue chips nas bolsas de valores. Todavia, setores mais dinâmicos da economia - informática, telecomunicações ou biotecnologia - despertam hoje um apelo mais forte no investidor do que uma mina deste ou daquele bem mineral. Esta tem sido a ótica do investidor norte-americano em Wall Street ou em Chicago nos últimos tempos, influenciando o comportamento empresarial e o planejamento das grandes empresas.

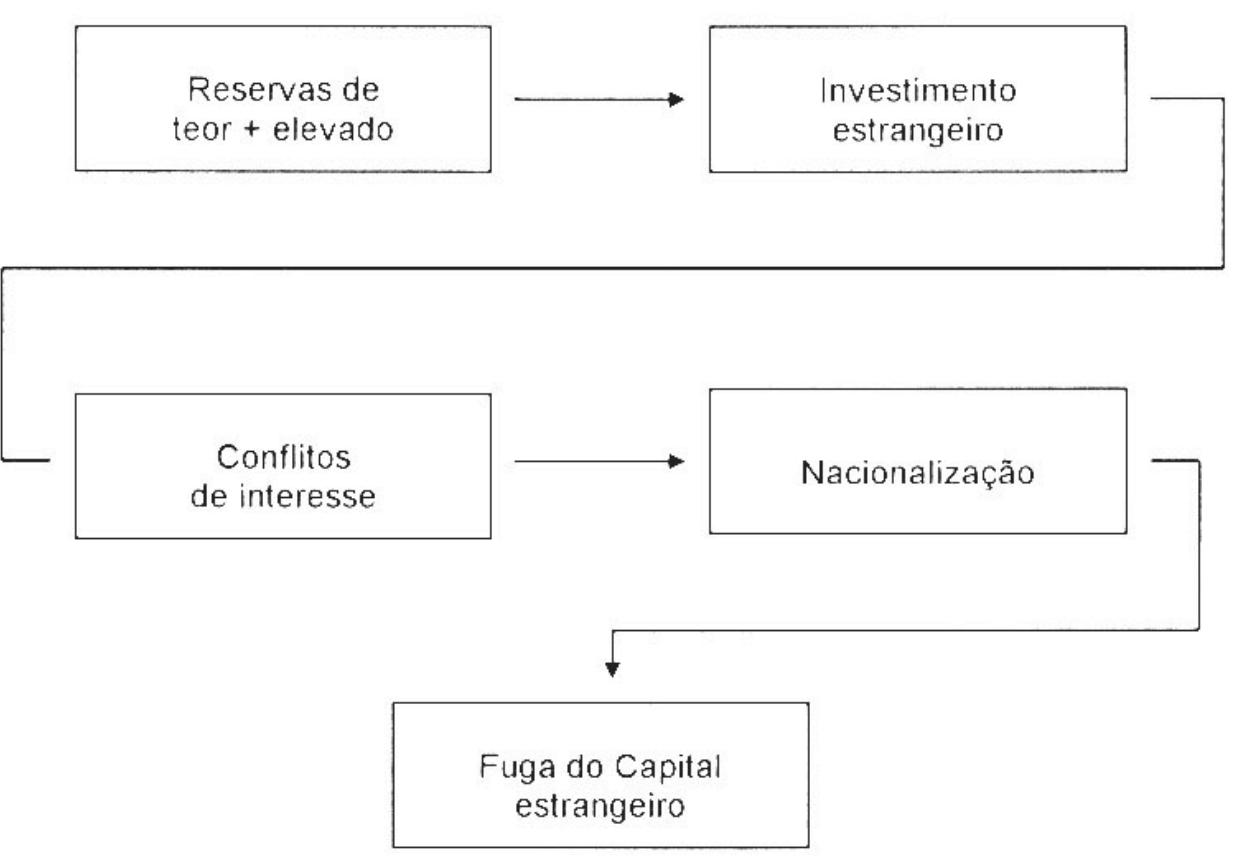

Figura 2: Modelo prevalecente nos países em desenvolvimento até as investidas da OPEP, em 1973 

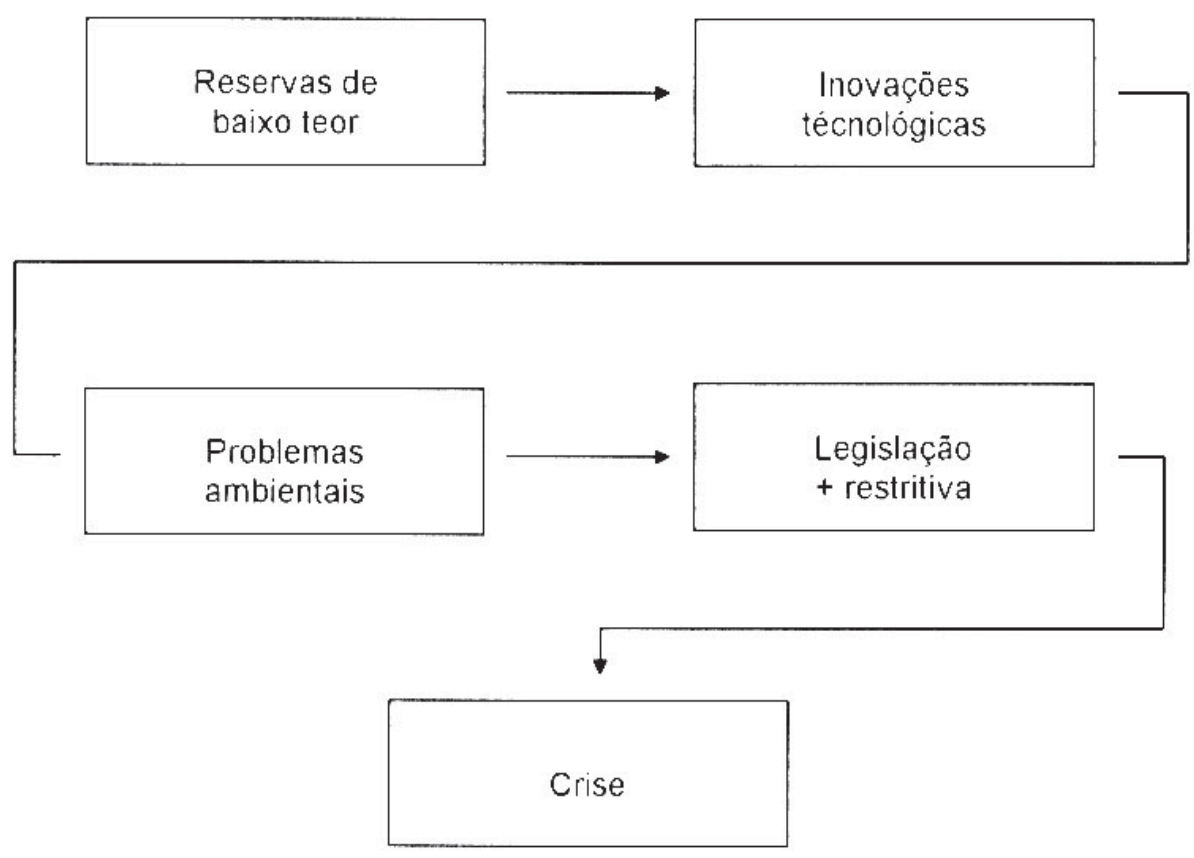

Figura 3: Modelo em crise durante a década de 80 nos países desenvolvidos
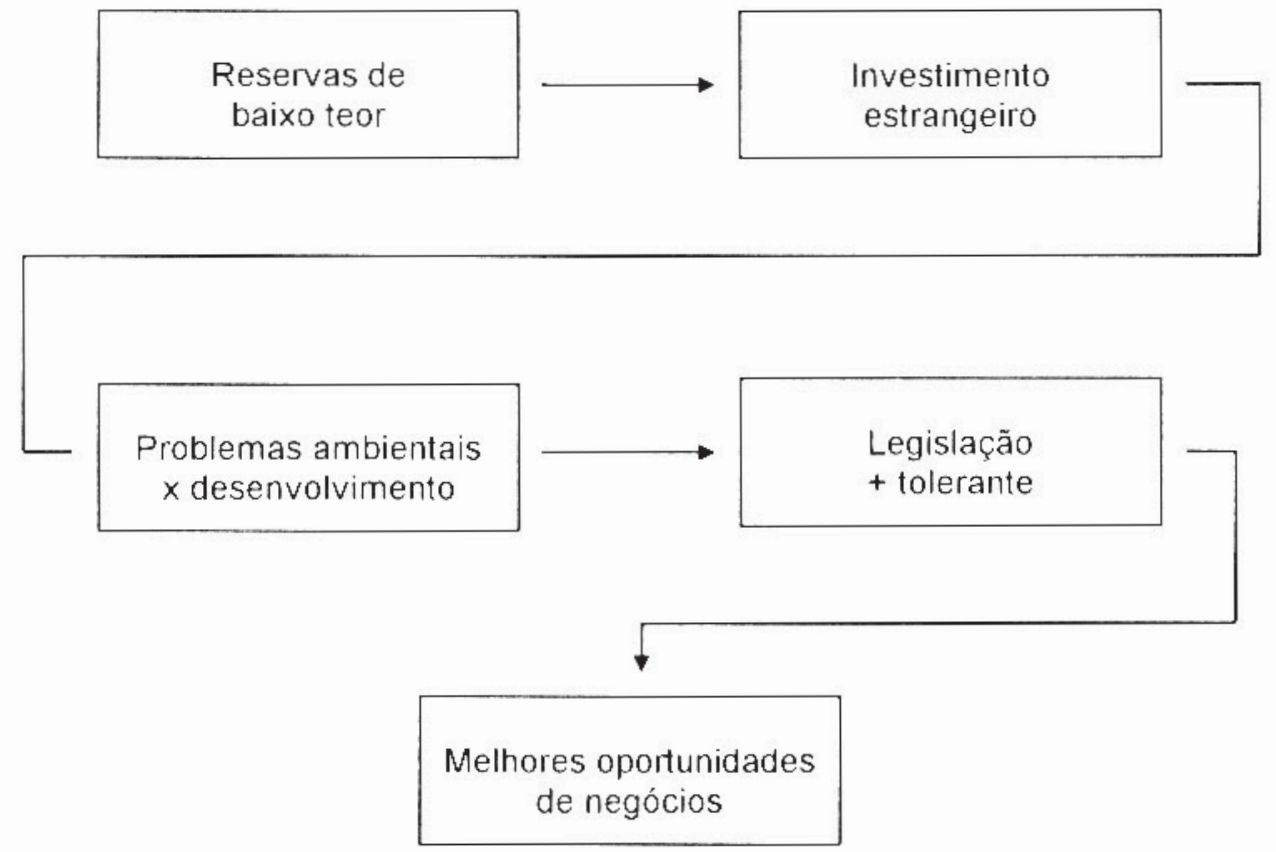

Figura 4: Modelo emergente durante a década de 80 nos países em desenvolvimento 


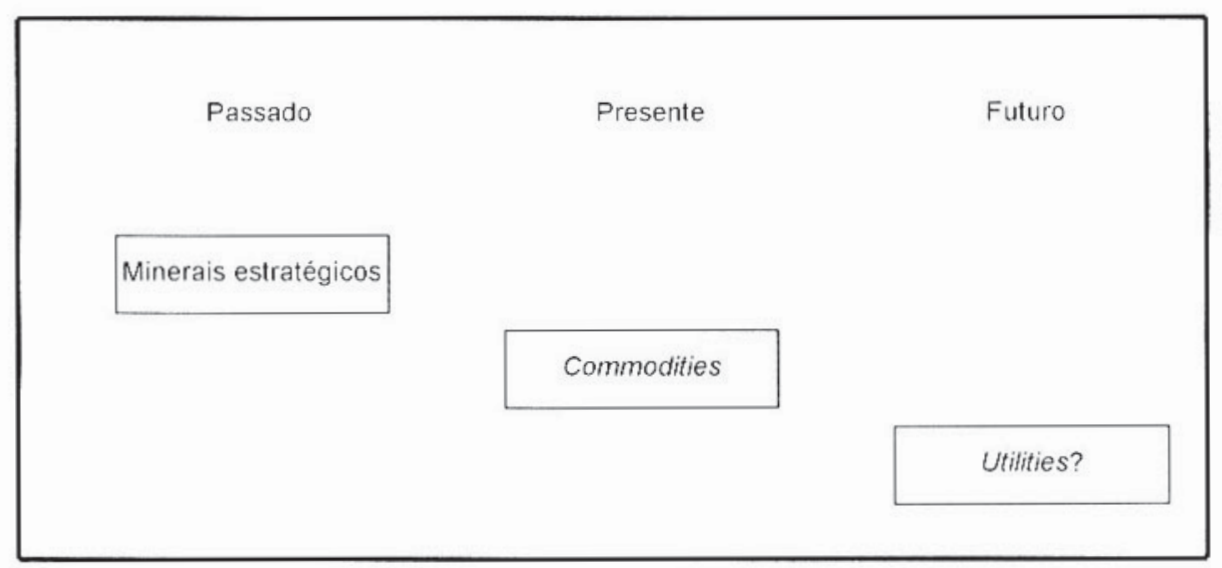

Figura 5: Evolução do status dos bens minerais

\section{Os bens minerais ainda são estratégicos?}

A conotação de mineral estratégico sempre teve as suas raízes fundamentadas em dois conceitos básicos: escassez (natural ou artificial) de recursos e possibilidade de confronto militar. Estando o mundo atualmente em situação de superoferta da grande maioria dos bens minerais, o comércio internacional encarrega-se placidamente de promover o equilíbrio entre oferta e demanda, sem rivalidade aguda entre as potências que possam ameaçar tal equilíbrio. Em segundo lugar, o fim da Guerra Fria tornou desnecessária a auto-suficiência ou a formação de estoques estratégicos de bens minerais e de outras commodities. Segundo alguns autores, dentre os quais se destaca o professor Lester Thurow (1993), "os preços das matérias-primas em 1990 eram 30\% mais baratos do que em 1980 e quase $40 \%$ abaixo do que eram em 1970. A revolução da ciência dos materiais atualmente em curso vai acelerar nos próximos anos, e novas reduções são esperadas no uso de quase todos recursos naturais por unidade de PNB. Fornecedores de matérias-primas naturais localizados no Terceiro Mundo encontrarão mercados cada vez menores para seus recursos cada vez mais baratos".

Apesar de se constatar crescente desinteresse do empresariado norte-americano pela mineração, do lado do governo a situação não é tão simples. O Departamento de Estado tem sob sua égide um programa de acompanhamento de questões envolvendo bens minerais, com destaque especial para os seguintes pontos (United States Geological Surveys - USGS, s/d.):

- privatização de empresas de mineração estatais;

- legislação e regulamentos afetando investimentos em mineração, incluindo regulamentos ambientais;

- atividades de companhias de mineração estrangeiras; 
- descoberta e desenvolvimento de jazidas de classe internacional;

- regulamentos ambientais;

- mudanças nos padrões de comércio.

O elo de ligação do Departamento de Estado com o USGS é o Minerals Information Team - MIT, que coleta e analisa informações sobre produção, comércio e consumo de minerais em todo o mundo. Seus country specialists podem responder a quaisquer questões relacionadas com minerais sobre um determinado país. O Departamento de Estado desenvolve trabalhos de forma estreita com geólogos, economistas e engenheiros de minas do USGS na análise de questões ligadas a minerais e em tomada de decisões. Em contraste gritante com esta postura, o governo brasileiro vem insistindo que a ênfase do nosso governo deve ser em tecnologia de ponta, já que os minerais são coisa do passado. Trata-se de ignorância ou arrogância?

No tocante à cooperação internacional, o governo dos EUA, por intermédio do USGS, participa de um grupo de trabalho intitulado International Studies of Mineral Issues (USGS, 1997) no qual, os outros membros são:

- África do Sul - Department of Mineral and Energy Affairs;

- Alemanha - Bundesanstalt für Geowissenschaften und Rohstoffe (BGR);

- Austrália - Department of Primary Industries and Energy;

- Canadá - Department of Natural Resources (NRCan);

- Reino Unido - Natural Environment Research Council (British Geological Survey);

O objetivo desse grupo de trabalho é a realização de estudos de cooperação visando a questões globais relacionadas com o desenvolvimento sustentável de recursos minerais e o suprimento de commodities minerais necessárias para atender às demandas e as preocupações ambientais de uma população mundial crescente. A necessidade da constituição do grupo de trabalho partiu da constatação de que uma grande proporção da produção atual e num futuro próximo provém de um pequeno número de grandes jazidas distribuídas no mundo. Como resultado desse trabalho conjunto, foram publicadas 14 circulares do USGS abrangendo os seguintes bens minerais:

$$
\begin{aligned}
& \text { - manganês } \\
& \text { - cromo } \\
& \text { - fosfato } \\
& \text { - níquel } \\
& \text { - metais do grupo da platina } \\
& \text { - cobalto } \\
& \text { - titânio }
\end{aligned}
$$

$$
\begin{aligned}
& \text { - grafita natural } \\
& \text { - lítio } \\
& \text { - estanho } \\
& \text { - vanádio } \\
& \text { - zircônio } \\
& \text { - nióbio-tântalo } \\
& \text { - óxidos de terras-raras }
\end{aligned}
$$


Observa-se que o Brasil possui importantes reservas de grande parte desses bens minerais, principalmente de nióbio, mas o governo parece disposto a ignorar a situação na ânsia de tornar a nação moderna e, portanto, desinteressada no destino de algo tão banal como aquilo que provém de atividade extrativa (Machado, 1997b).

Outro exemplo corresponde ao capítulo sobre o Brasil da publicação World Fact Book, da Agência Central de Inteligência (CIA), dos EUA, que menciona o nosso país como portador de abundantes recursos naturais, nos quais sobressaem minérios de variados tipos. É realmente triste verificar que governos têm percepção mais adequada desses recursos, enquanto órgãos oficiais do Brasil tentam minimizar o seu valor nas relações internacionais, em troca de uma suposta coerência em apressadas operações de privatização de recursos naturais valiosos que pertenciam a várias gerações atuais e futuras de cidadãos brasileiros.

Em resumo, os bens minerais não têm mais a mesma conotação de estratégicos, dada durante as duas Guerras Mundiais ou ao longo da Guerra Fria. Não obstante, o conceito de estratégico não se tornou obsoleto ou inócuo, à medida em que cada país possui vantagens e desvantagens competitivas na área da geopolítica ou da geoeconomia, e em torno dessas vantagens é que os governantes e o corpo diplomático exercerão o seu papel legítimo nas tensas negociações internacionais. Ao falhar nessa missão, o governo pode cometer danos irreparáveis à geração atual e às gerações futuras.

\section{A legislação ambiental no Brasil e no mundo}

Desde o início da década de 70, os países desenvolvidos aprenderam uma dura lição: a continuarem as práticas industriais em vigor, os danos ambientais se tornariam irreversíveis, comprometendo seriamente o bem-estar de suas populações. Conscientes desses riscos, deram uma guinada em sua política industrial, assumindo posições restritivas à atuação do setor produtivo.

A mineração, como não poderia deixar de ser, não fugiu aos dispositivos da nova legislação, em virtude do seu impacto sobre o solo, os recursos hídricos, o ar e a paisagem. No início, a grande dificuldade consistia em demonstrar, com base científica, a relação causa-efeito entre os processos produtivos e o impacto ambiental deles resultante. Com o passar do tempo, os instrumentos de medição dos impactos foram se aperfeiçoando, de modo que as agências ambientais dispõem hoje de meios mais eficazes para exigir o cumprimento das normas estabelecidas, com o mínimo de questionamento por parte dos eventuais poluidores.

Tanto quanto na disseminação de novos hábitos e costumes em geral, a questão ambiental chega com algum atraso aos países menos desenvolvidos. Além disso, lamentavelmente o governo procura conciliar de forma excessiva as reivindicações da mineração organizada, acarretando às vezes conseqüências indesejáveis para as gerações futuras. Em muitos exemplos, a tese do desenvolvimento sustentável converte-se em apenas mais uma figura de retórica do poder público. 
A Constituição de 1988 estabelece em seu artigo 225, parágrafo $2^{\circ}$ : "aquele que explorar recursos minerais fica obrigado a recuperar o meio ambiente degradado, de acordo com solução técnica exigida pelo órgão público competente, na forma da lei." Além disso, o Decreto n 97.632 de 10 de abril de 1989, exige que, ao apresentar o EIA/RIMA (Estudo de Impacto Ambiental/Relatório de Impacto Ambiental), o responsável pelo empreendimento de mineração deverá solicitar a aprovação do competente plano de recuperação de área degradada. Posteriormente, pelo Decreto n ${ }^{\circ} 99.274$ de 6 de junho de 1990, foi estipulado que todo empreendimento mineiro será obrigado a obter do órgão estadual competente três licenças: licença prévia, licença de instalação e licença de operação. No tocante às penalidades previstas, o mesmo decreto estabelece multas que variam de 61,70 a $6.170 \mathrm{BTN}$ (3), de acordo com o grau de degradação ambiental causada. Nos casos mais graves, a multa nesses valores poderá ser diária. Quando as multas forem superiores a 3.085 BTN, caberá recurso ex officio para o Conselho Nacional do Meio Ambiente.

De modo geral, os países latino-americanos aplicam uma legislação ambiental muito menos rigorosa do que as nações anglo-saxônicas. Dentro da ótica neoliberal prevalecente nesses países, uma legislação coercitiva não seria compatível com o novo papel a ser desempenhado pelo empresariado dentro do paradigma do Estado mínimo. Dir-se-ia que a principal falha no comportamento dos órgãos ambientais da América Latina é a sua incapacidade de executar efetivamente a legislação, ou seja, promover o enforcement para coibir abusos. As autoridades costumam ser lenientes para com os erros ou omissões dos criadores de riquezas, mesmo que a sociedade como um todo venha a pagar pelas conseqüências desses erros. Em outras palavras, a maioria das autoridades aceita complacentemente a externalização dos danos ambientais.

Em contraste com a prática de países latino-americanos, Canadá, Estados Unidos e Austrália vêm aperfeiçoando uma legislação crescentemente restritiva com relação aos danos ambientais causados pela mineração. Desde o início da década de 90 entrou em vigor um dispositivo extremamente sério, penalizando as empresas de mineração, mas buscando beneficiar a sociedade desses países. Trata-se da exigência de apresentação do plano de fechamento da mina, acompanhado de orçamento, ainda durante a fase de desenvolvimento. Tal exigência significa que, antes de iniciar a produção, o responsável pelo empreendimento mineiro terá de se comprometer com a execução do plano de fechamento da mina. Para selar o compromisso, o empreendedor terá de depositar uma caução em títulos do Tesouro, pagamento à vista ou outra modalidade aceita pelo governo, de modo a garantir o cumprimento do plano de fechamento da mina, conforme aprovado pelas autoridades competentes. Por motivos óbvios, não são aceitas ações em bolsa, seja do empreendedor, seja de quaisquer empresas. Esse aspecto pode significar um desembolso prévio de US\$ 20 milhões, US\$ 30 milhões, ou mais, dependendo das características do projeto. Desse modo, o fluxo de caixa de cada projeto incorpora, em decorrência da nova legislação, um ônus que não era contemplado anteriormente, o qual pode comprometer a viabilidade de um grande número de empreendimentos. É fácil de 
compreender por quê o exame de oportunidades minerais nos países em desenvolvimento se tornou irresistível na década atual. A preocupação da sociedade norteamericana com a mineração é legítima, considerando que o passivo ambiental registrado nos EUA é algo impressionante, conforme os dados apresentados no quadro 2, abrangendo mais de 550 mil minas abandonadas. Ao investigar os custos de proteção ambiental em empreendimentos mineiros, Clark (1993) chegou às estimativas constantes do quadro 3 .

Atualmente existe dentro dos EUA um pesado lobby ambientalista, cuja militância tem preocupado a indústria em geral. As suas atividades no ano de 1994 atingiram um orçamento na faixa de US\$ 894 milhões, conforme ilustrado no quadro 4. O total de sócios dessas organizações alcança um número superior a 12.321.350 indivíduos. As mesmas organizações empregam mais de 5.665 pessoas.

A divulgação, por meio da Environmental Protection Agency (EPA) (1997), de que 59 minas abandonadas estão catalogadas na National Priorities List do Programa Superfund, põe a mineração na ordem do dia dessas ONGs. Para complicar ainda mais a questão, o custo da recuperação ambiental de cerca de 550 mil minas abandonadas estaria na faixa entre US\$ 32,7 bilhões e US\$ 71,5 bilhões (Bumpers, 1997), segundo estimativa do Mineral Policy Center, ONG sediada em Washington, D.C. (quadro 5).

Em perspectiva mais ampla, abrangendo países de renda per capita elevada, de renda média e aqueles mais pobres, resumo minha preocupação com a questão ambiental no quadro 6 , no qual são visualizadas as tendências observadas na última década. Não obstante as boas intenções demonstradas por inúmeras delegações e chefes de Estado na Rio 92 ou na Conferência Rio+5, a questão não deixa de ser preocupante em função das práticas adotadas.

Quadro 2

Cadastro das minas abandonadas nos Estados Unidos

\begin{tabular}{|lcc|}
\hline \multicolumn{1}{|c|}{ Minas } & Quantidade & Porcentagem \\
\hline Total de abandonadas & 557.650 & 100 \\
Benignas ou recuperadas & 197.500 & 35 \\
Exigindo remediação da paisagem & 231.900 & 42 \\
Apresentando problemas ambientais diversos & 128.250 & 23 \\
Provocando problemas para a rede hídrica & 14.400 * & 2,6 * \\
Provocando problemas para o lençol freático & 500 * & $<0,1$ * \\
\hline
\end{tabular}

* Incluídas na categoria de "Minas apresentando problemas ambientais diversos"

Fonte: Mining Engineering, abril 1994 
Quadro 3

Custos de proteção ambiental (valores médios)

\begin{tabular}{|lr|}
\hline Atividade & \multicolumn{1}{c|}{ US\$ } \\
\hline Exploração & $0-250.000$ \\
Desenvolvimento & $250.000-1.000 .000$ \\
Lavra & $1.000 .000-10.000 .000$ \\
Beneficiamento & $10.000 .000-50.000 .000$ \\
Metalurgia extrativa & $>50.000 .000$ \\
\hline
\end{tabular}

Fonte: Clark, 1993

Quadro 4

O lobby ambientalista nos EUA

\begin{tabular}{|c|c|c|c|}
\hline Nome & Sócios & Staff & $\begin{array}{c}\text { Orçamento } \\
\text { (1994) US\$ milhões }\end{array}$ \\
\hline \multicolumn{4}{|l|}{ Grupos de acão direta } \\
\hline Greenpeace & 1.700 .000 & 207 & 45 \\
\hline Earth Island Institute & 15.000 & 42 & 3,8 \\
\hline Sea Shepherd Conservation Soc. & 25.000 & 20 & 0,53 \\
\hline Rainforest Action Network & 30.000 & 27 & 2,0 \\
\hline $\begin{array}{l}\text { Total } \\
\text { Acões litiaiosas / Lobby / Relacões públicas }\end{array}$ & 1.770 .000 & 296 & 51,3 \\
\hline National Wildlife Fed. & 1.719 .000 & 607 & 96,3 \\
\hline Ralph Nader Affiliates & $?$ & $?$ & 87,0 \\
\hline (Citizen Action) & 3.000 .000 & 250 & 37,0 \\
\hline (Clean Water Actions) & 1.100 .000 & 500 & 15,0 \\
\hline World Wildlife Fund & 1.200 .000 & 290 & 79,0 \\
\hline National Audubon Soc. & 540.000 & 300 & 43,0 \\
\hline Sierra Club & 570.000 & 250 & 45,0 \\
\hline Natural Resources Defense Council & 170.000 & 174 & 20,0 \\
\hline Environmental Defense Fund & 250.000 & 150 & 23,3 \\
\hline World Resources Institute & n.d. & 112 & 12,9 \\
\hline Sierra Club Legal Defense Fund & n.d. & 94 & 10,8 \\
\hline Defenders of Wildlife & 101.000 & 54 & 6,5 \\
\hline Union of Concerned Scientists & 80.000 & 50 & 4,0 \\
\hline Worldwatch & n.d. & 30 & 3,6 \\
\hline Friends of the Earth & 37.850 & 29 & 3,0 \\
\hline Citizen's Clearing for Hazardous Wste & 8.000 & 8 & 0,95 \\
\hline Environmental Action & 10.000 & 11 & 1,0 \\
\hline Rainforest Alliance & 15.000 & 30 & 1,0 \\
\hline $\begin{array}{l}\text { Total } \\
\text { Gestão Territorial / Aquisiçãa }\end{array}$ & $8.800 .850+$ & $2.939+$ & 437,4 \\
\hline The Nature Conservancy & 819.000 & 1.762 & 303,0 \\
\hline Ducks Unlimited & 550.000 & 250 & 68,0 \\
\hline The Wilderness Soc. & 275.000 & 108 & 16,3 \\
\hline Conservation International & 6.500 & 260 & 13,8 \\
\hline African Wildlife Foundation & 100.000 & 50 & 3,7 \\
\hline Total & 1.750 .500 & 2.430 & 404,8 \\
\hline Total geral & $12.321 .350+$ & $5.665+$ & 893,5 \\
\hline
\end{tabular}

Fonte: Mining Voice, Sep./Oct. 1996, p.2 
Figura 6

A mineração e o meio ambiente - Grandes questões desafiando diferentes países

\begin{tabular}{|c|c|c|c|c|c|c|}
\hline & $\begin{array}{r}\text { Paises/ } \\
\text { Questões importantes }\end{array}$ & $\begin{array}{c}\text { Japão, Alemanha e } \\
\text { Suiça }\end{array}$ & EUA & $\begin{array}{c}\text { Canadá, Suécia e } \\
\text { Finlândia }\end{array}$ & Brasil, México e Chile & Paises muito pobres \\
\hline & Expecxtativas & $\begin{array}{l}\text { Melhor qualidade de } \\
\text { vida }\end{array}$ & $\begin{array}{l}\text { Melhor qualidade de } \\
\text { vida }\end{array}$ & $\begin{array}{l}\text { Melhor qualidade de } \\
\text { vida }\end{array}$ & $\begin{array}{l}\text { Desenvolvimento } \\
\text { econômico, se } \\
\text { possivel }\end{array}$ & $\begin{array}{l}\text { Sobrevivência na era } \\
\text { da globalização }\end{array}$ \\
\hline & Status da mineração & Inexpressivo & $\begin{array}{l}\text { Em deterioração, os } \\
\text { investidores estão } \\
\text { abandonando a } \\
\text { mineração devido a } \\
\text { outras preferências }\end{array}$ & $\begin{array}{l}\text { Ainda uma fonte } \\
\text { importante de receita, } \\
\text { divisas, emprego e } \\
\text { desenvolvimento } \\
\text { regional }\end{array}$ & $\begin{array}{l}\text { Importante para o } \\
\text { desenvolvimento de } \\
\text { áreas remotas ou } \\
\text { mesmo para o } \\
\text { desenvolvimento } \\
\text { nacional }\end{array}$ & $\begin{array}{l}\text { Às vezes, a única } \\
\text { fonte importante de } \\
\text { receita e divisas }\end{array}$ \\
\hline & Legislação ambiental & $\begin{array}{l}\text { Muito restritiva, a } \\
\text { mineração não } \\
\text { consegue competir } \\
\text { com outros usos do } \\
\text { solo }\end{array}$ & $\begin{array}{l}\text { Restritiva, o } \\
\text { tratamento da } \\
\text { questão das minas } \\
\text { abandonadas veio } \\
\text { complicar ainda mais; } \\
\text { mudanças na velha } \\
\text { Mining Law (1872) } \\
\text { agravam os } \\
\text { problemas já } \\
\text { existentes }\end{array}$ & $\begin{array}{l}\text { Restritiva, sendo } \\
\text { dificil às vezes } \\
\text { balancear as } \\
\text { necessidades } \\
\text { econômicas desses } \\
\text { paises e as } \\
\text { aspirações dos seus } \\
\text { cidadãos por um meio } \\
\text { ambiente melhor }\end{array}$ & $\begin{array}{l}\text { Regulamentos } \\
\text { tolerantes, de modo } \\
\text { geral, empregos, } \\
\text { salários, infra- } \\
\text { estrutura social etc. } \\
\text { são considerados } \\
\text { mais importantes que } \\
\text { o controle da poluição }\end{array}$ & $\begin{array}{l}\text { Regulamentos } \\
\text { tolerantes (quando } \\
\text { existentes); tais } \\
\text { paises encontram-se } \\
\text { muitas vezes num } \\
\text { estágo no qual o } \\
\text { desenvolvimento } \\
\text { econômico a qualquer } \\
\text { custo é a única meta } \\
\text { possivel }\end{array}$ \\
\hline & Futuro provável & $\begin{array}{l}\text { Importadores } \\
\text { perpétuos de bens } \\
\text { minerais }\end{array}$ & $\begin{array}{l}\text { Mudando } \\
\text { gradualmente de } \\
\text { produtor para } \\
\text { importador de } \\
\text { minerais }\end{array}$ & $\begin{array}{l}\text { Em alguns círculos, a } \\
\text { mineração é } \\
\text { considerada uma } \\
\text { indústria do poente }\end{array}$ & $\begin{array}{l}\text { Muitos conflitos } \\
\text { futuros com relação } \\
\text { ao desenvolvimento } \\
\text { sustentável em } \\
\text { operações mineiras }\end{array}$ & $\begin{array}{l}\text { Para alguns desses } \\
\text { paises paira o sério } \\
\text { risco de se tornarem } \\
\text { refúgios de poluição }\end{array}$ \\
\hline
\end{tabular}


Quadro 5 - Passivo ambiental dos EUA (mineração)

\begin{tabular}{|lc|}
\hline Minas abandonadas & Quantidade \\
\hline Em terras públicas & 250.000 minas \\
Em todo país & 557.000 minas \\
Estimativa de orçamento para recuperação de todas & US $\$ 32,7-$ US $\$ 71,5$ bilhões \\
\hline
\end{tabular}

Fonte: Bumpers, 1997

\section{Cenários para a indústria mineral brasileira}

O ambiente da mineração tornou-se extremamente competitivo nos últimos anos, acompanhando as tendências da economia global neste final de século. Dentre os vários fatores responsáveis pelo fenômeno destaca-se, em primeiro plano, a redução na demanda internacional, que teve como desdobramentos principais o excesso de capacidade instalada e a queda generalizada dos preços dos bens minerais, conforme já referido (Machado, 1994).

Tal quadro foi ainda mais acentuado pela manutenção, ao longo da década de 80, da expansão de investimentos estatais em mineração na América Latina e na África, a despeito das condições desfavoráveis para os produtos minerais. Além disso, o aperfeiçoamento e a ampliação das práticas de reciclagem e substituição de metais, reduzindo a demanda de bens primários; o aparecimento e a afluência dos novos materiais, baseados em recursos mais abundantes e melhor distribuídos entre os países; e, finalmente, as vendas bruscas dos estoques acumulados pelos países exsocialistas, empenhados em amenizar seus problemas de caixa face à crise surgida após as transformações ocorridas no Leste Europeu, acabaram por agravar ainda mais o referido quadro.

Países como Estados Unidos e Canadá vêm lutando pela sobrevivência da sua indústria mineral mediante o aumento de produtividade, a redução de custos, as inovações tecnológicas e a capacidade de adaptar-se às crescentes exigências de uma legislação ambiental severa e penalizada com onerosos encargos. Além disso, mudanças importantes na legislação norte-americana estão prestes a introduzir royalties sobre a produção de bens minerais metálicos em terras federais, inexistentes desde o longínquo ano de 1872 (Bumpers, 1997).

Em conseqüência desses fatos, está em pleno curso um novo ciclo favorável ao desenvolvimento de novos empreendimentos no setor minero-metalúrgico em países como o Brasil, dotado de potencial geológico privilegiado e de infra-estrutura e condições que poucos países em desenvolvimento poderiam oferecer aos investidores interessados (Ferraz et al., 1995).

Neste ambiente, as jazidas de classe internacional, a despeito da formação de blocos regionais de comércio em todo o mundo, ainda têm uma importância que 
ultrapassa as fronteiras desses blocos. De fato, as vantagens inerentes à exploração de jazidas de alto teor ou baixo custo de produção são e serão, na maioria dos casos, insuperáveis, mesmo considerando o estado-da-arte atual da tecnologia mineral nos países mais avançados; além disso, a concepção básica dessas mega-estruturas econômicas é mais direcionada para as necessidades dos setores secundário e terciário da economia. Tudo isso indica, inexoravelmente, que a migração da indústria mineral para os países em desenvolvimento vai se acentuar nas próximas décadas.

A flexibilização da política e da legislação mineral, ocorrida ou em curso, em países como México, Chile, Peru, Bolívia e até mesmo Cuba, finalmente aconteceu no Brasil após as esperadas emendas constitucionais. Em sintonia com esse evento, cerca de 70 países em todo o mundo promoveram adaptações ou ajustes visando atrair avidamente o capital estrangeiro. Infelizmente, esta corrida de países em desenvolvimento, ao lado de alguns desenvolvidos, sinaliza para ampliar ainda mais a capacidade instalada, o que irá acirrar a superoferta de diversos bens minerais no início do próximo século.

Em conseqüência de nossas características geológicas e metalogenéticas, o maior desafio para o crescimento das exportações brasileiras reside na competição com alguns países como Austrália, China, Índia, Rússia e outros membros da CEI, além das economias mineiras tradicionais. Com exceção do ouro, os países latinoamericanos possuem um patrimônio mineral que é mais ou menos complementar ao nosso, por conseguinte com reduzido poder de competição com o Brasil na arena internacional.

Num horizonte de longo prazo, se estiverem corretas algumas previsões da Organização para a Cooperação e Desenvolvimento Econômico (OCDE) (4), o Brasil terá em 2010 uma população de 248 milhões de habitantes, um PIB de US\$ 1.398 bilhões e uma renda per capita de US\$ 5.637. Mantida a tendência histórica, a produção mineral poderá atingir um valor próximo de US\$ 28 bilhões ( $2 \%$ do PIB) no ano 2010.

O desempenho da indústria mineral brasileira na segunda metade da década de 90 dependerá da retomada do crescimento econômico do país, assim como da exploração de oportunidades no comércio exterior, principalmente em função de empreendimentos alicerçados em jazidas de classe internacional, os quais poderão resistir a movimentos cíclicos na curva de preços e na demanda do mercado externo. Basicamente, três cenários podem ser vislumbrados para o futuro.

\section{Cenário A}

Se a política econômica do governo escolher a retomada do desenvolvimento econômico como uma de suas prioridades, o consumo de bens minerais essenciais à ampliação de infra-estrutura, programas de habitação, saneamento básico, implantação de novos pólos industriais etc., terá um ritmo de crescimento mais acelerado. A redefinição do papel do Estado no período pós-privatização da Companhia Vale do Rio Doce torna-se um item extremamente relevante da agenda política e terá 
fortes desdobramentos sobre os investimentos a serem realizados em infra-estrutura, que deverão provir, naturalmente, de fontes do setor privado. Desse modo, os recursos oficiais seriam canalizados predominantemente para as áreas de saúde, previdência, educação, segurança entre outras carentes de apoio governamental.

\section{Cenário B}

Um cenário mais conservador para os próximos anos significaria a continuação do crescimento da produção mineral acompanhando a evolução do PIB no caso do mercado interno, ou a evolução da produção industrial dos países desenvolvidos no caso do mercado externo. Quanto ao mercado interno, prevê-se que as taxas mais prováveis de crescimento da produção de alguns bens minerais (brita, areia, argila e calcário), no curto prazo, irão se aproximar do valor de $3-4 \%$ ao ano. No que se refere ao mercado externo, as taxas de crescimento esperadas para aqueles bens minerais mais importantes da nossa pauta de exportação (minério de ferro, bauxita/alumínio, minério de manganês, ferro-nióbio) serão pouco inferiores a $2 \%$ ao ano (5).

\section{Cenário C}

O pior cenário seria aquele em que o governo fosse incapaz de manter as atuais taxas de crescimento, em função de problemas múltiplos derivados da falta de recursos orçamentários, efeito dominó da crise asiática, aumento da sonegação fiscal, crescimento incontrolável da economia informal, desarmonia entre o Executivo e o Legislativo comprometendo as reformas necessárias, volta da ciranda financeira e escassez de investimentos estrangeiros em atividades produtivas. Ainda assim, podese esperar que o crescimento médio da produção mineral tenha um desempenho melhor que o crescimento do PIB, embora a taxas menores do que aquelas ocorridas na década de 80 .

Valorizar o mercado interno deverá ser uma das prioridades da política econômica oficial. Todos os esforços devem ser dispendidos para garantir a melhoria do poder aquisitivo do consumidor brasileiro e, também, da sua qualidade de vida. O governo deve modernizar e tornar mais eficiente e eficaz a sua estrutura no campo político-institucional, de modo a remover os empecilhos que vêm dificultando as atividades da iniciativa privada, responsável que é pelo crescimento da produção mineral brasileira. Resolvidos esses pontos, deverá incentivar prioritariamente dois programas de grande alcance para o setor:

- expandir os distritos mineiros já existentes, revelando todo o seu potencial e ampliando e aprofundando os seus vínculos com a economia local ou regional;

- dar continuidade à abertura de novos empreendimentos minero-metalúrgicos na Amazônia, ou expandir aqueles já em operação, considerando o seu vasto potencial e as necessidades de sua população. 
O governo deverá ainda, conciliar a implantação de novos empreendimentos, em particular na Amazônia, com outras prioridades definidas para o uso e ocupação do solo, em sintonia com as determinações do Programa de Zoneamento Ecológico-Econômico. É importante, contudo, que as prioridades desse zoneamento sejam reavaliadas periodicamente, a fim de propiciar que novas áreas mineralizadas venham a se incorporar a planos futuros de desenvolvimento regional, quando for o caso.

Ao implementar o Plano Plurianual para o Desenvolvimento do Setor Mineral, espera-se que o governo venha a promover estudos detalhados sobre algumas questões críticas como:

- modernização institucional dos órgãos competentes;

- continuação dos levantamentos geológicos básicos;

- identificação de jazidas de classe internacional;

- garimpagem;

- mineração em terras indígenas;

- mineração em faixas de fronteira;

- mineração em áreas urbanas;

- aperfeiçoamento das normas de proteção ambiental;

- recuperação de áreas degradadas pela mineração;

- desenvolvimento de tecnologias de proteção ambiental;

- monitoramento da disponibilidade primária de bens minerais;

- tendências mundiais no consumo de bens minerais;

- informatização do setor mineral;

- competitividade internacional da indústria mineral brasileira.

Em suma, é chegado o esperado momento de o Governo Federal, em meio à criação de tantas agências reguladoras, dedicar maior atenção ao destino do nosso subsolo.

Notas

1 Comunicação oral do professor Hildebrando Herrmann.

2 O conceito de utility se aproxima bastante daquele empregado para os minerais de uso social, denominação freqüentemente utilizada no Brasil para os materiais de uso imediato na construção civil.

3 Equivalentes a US\$ 44,37 e US\$ 4.437, respectivamente, em junho de 1990.

4 Compreende: Alemanha, Austrália, Áustria, Bélgica, Canadá, Dinamarca, Espanha, 
Estados Unidos, Finlândia, França, Grécia, Holanda, Inglaterra, Itália, Irlanda, Islândia, Japão, Luxemburgo, México, Nova Zelândia, Portugal, Suécia, Suíça e Turquia.

5 A eclosão da crise asiática, em outubro de 1997, fatalmente terá um efeito negativo sobre essas taxas de crescimento.

Referências bibliográficas

BARBOZA, F.L.M. The mineral economy of Brazil. In: FIRST INTERNATIONAL SYMPOSIUM ON MINING AND DEVELOPMENT, Proceedings. Campinas, Unicamp, 10-13 jul. 1995, p. 21-34.

BRASIL. Departamento Nacional da Produção Mineral. Sumário Mineral, v. 1, Brasília, DNPM, 1996.

BRITO, O. \& ALVES, F. Títulos minerários - DNPM promete que vai reduzir burocracia. Brasil Mineral, n. 148, p. 40-48, mar. 1997.

BUMPERS, D. The Mining Law of 1872. U.S. Senate, Congressional Record S 4293, May 12, 1997 [On-line]. Disponível: http://rs9.loc.gov/cgi-bin/query/4?r105:./ temp/ r105C6uB:e12306:mining+law [23.05.97].

CLARK, A.L. Energy and mineral development: environment and economics. In: BROOKFIELD, H. \& BYRON, Y. (eds.) Southeast Asia's environmental future. Kuala Lumpur, Oxford University Press, 1993, p.75-102.

DORIAN, J.P. \& KORT, P.S. Joint mineral ventures in the former Soviet Union: prospects, problems and realities. Natural Resources Forum, v. 20, n. 3, p. 199-213, Aug. 1996.

EUA. United States Geological Survey. Mineral Resources Program. International Studies of Mineral Issues (formerly International Strategic Minerals Inventory), Mar. 1997 [On-line]. Disponível: http://minerals.er.usgs.gov/fact-sheets/ International.html [26.09.97].

EUA. United States Geological Survey. Mineral Resources Program. U.S. Department of State's interest in minerals issues, s/d. [On-line]. Disponível: http:// minerals.er.usgs.gov/fact-sheets/Dept_of_State.html [20.08.97]

EUA. United States Environmental Protection Agency - EPA. Superfund - your window to cleaning up the nation's hazardous waste sites. Dec. 1st., 1997 [On-line]. Disponível: http://www.epa.gov/superfund/ [22.12.97].

FERRAZ, C.P.; MACHADO, I.F. \& SUSLICK, S.B. Potential and challenges for the Brazilian mining industry. In: FIRST INTERNATIONAL SYMPOSIUM ON MINING AND DEVELOPMENT, Proceedings. Campinas, Unicamp, 10-13 jul. 1995, p.45-57.

GURMENDI, A.C. The mineral industry of Brazil. Reston, U.S. Geological Survey Minerals Information, 1996.

HARGREAVES, D.; EDEN-GREEN, M. \& DEVANEY, J. World index of resources and population. Hants, Dartmouth Publishing Co., 1994. 
MACHADO, I.F. A extinção do Bureau of Mines Brasil Mineral, n. 147, p. 28-32, jan./fev. 1997.

The CVRD privatisation: a hard victory for the government. Journal of Mineral Policy, Business and Environment-Raw Materials Report, v. 14, n. 4, p. 36-41, 1997.

(coord.). Cenários para a mineração do Brasil. Relatório Setorial Plano Plurianual para o Desenvolvimento do Setor Mineral - DNPM, 1994.

NATIONAL Research Council (U.S.). Committee on Competitiveness of the U.S. Minerals and Metals Industry. Competitiveness of the U.S. minerals and metals industry. Washington, 1990.

RTZ Mineração Ltda. Reabilitando áreas mineradas - Fechamento da Mina Cabaçal Mineração Manati. Brasília, RTZ Mineração, jan. 1994.

THUROW, L. Head to head: the coming economic battle among Japan, Europe and America. New York, Warner Books, 1993.

WARHURST, A. \& BRIDGE, G. Economic liberalisation, innovation, and technology transfer: opportunities for cleaner production in the minerals industry. Natural Resources Forum, v. 21, n. 1, p. 1-12, Feb. 1997.

RESUMO - A INDÚSTRIA mineral brasileira é analisada, de modo sucinto, face aos desafios impostos pela globalização contemporânea. As mudanças profundas ocorridas no contexto internacional na última década, abrangendo as esferas política, econômica, social e institucional, exigem uma reflexão aprofundada sobre o papel a ser desempenhado pelo Brasil no comércio internacional de bens minerais. De um lado, as oportunidades de aproveitamento de jazidas de classe internacional, principalmente na Amazônia, são bastante promissoras. Por outro, não se deve ignorar que: a explotação dessas reservas terá de obedecer a critérios de sustentabilidade, seguindo paradigmas já adotados em países desenvolvidos; o Brasil terá de garantir a sua competitividade diante dos seus principais concorrentes (Austrália, CEI, China e Índia). A questão dos minerais estratégicos é também abordada, com ênfase nas preocupações demonstradas pelo Departamento de Estado dos EUA. Finalmente, são alinhados três cenários possíveis para o desempenho futuro da mineração brasileira, instando-se o governo a dedicar maior atenção ao destino do nosso subsolo.

ABSTRACT - THE MINERAL industry of Brazil is briefly analysed vis-à-vis the challenges imposed by the cruenta globalization process. The profound changes that occurred in the international framework during the last decade, encompassing the political, economic, social, and institutional structures, demand a thorough appraisal about the role to be played by Brazil in the international market of mineral commodities. On one hand, the opportunities open for world class deposits, mainly in the Amazon, are very promising. On the other hand, it is mandatory to take into account that: the exploitation of these reserves shall comply with sound sustainability criteria, following guidelines already adopted by some developed countries; Brazil will have to demonstrate its competitiveness among the major competitors (Australia, China, CIS and India). The issue of strategic 
minerals is also discussed, giving emphasis to the concerns raised by the U.S. Department of State. Finally, three possible scenarios pointing to the future behavior of the mineral industry of Brazil are highlighted, and the government is solicited to give special consideration to our mineral resources.

Iran Ferreira Machado é professor convidado do Departamento de Administração e Política de Recursos Minerais do Instituto de Geociências da Unicamp, e autor do livro Recursos Minerais, Politica e Sociedade. 